\section{„Wilhelm Conrad Röntgen ist meine Passion“}

Laufen für Wilhelm Conrad: Dr. Michael Finkenstaedt, niedergelassener Radiologe aus Hamburg, hat drei Mal in Folge den RöKo-Spendenlauf zugunsten des Röntgen-Geburtshauses gewonnen. Im Interview verrät er, warum er als Platinspender auch noch regelmäßig beim Deutschen Röntgenkongress die Laufschuhe schnürt und welche Bedeutung der Begründer der Radiologie für ihn hat.

Herr Dr. Finkenstaedt, Sie sind begeisterter Läufer - haben Sie vielleicht eine „Paradedisziplin“?

Seit 1975 mache ich Sport - und meine Spezialität sind Orientierungsläufe. Dort ist man mit Karte und Kompass im Wald unterwegs und muss vorgeschriebene Kontrollpunkte innerhalb einer bestimmten Zeit erreichen. Die genaue Strecke bleibt jedem Läufer überlassen. Man muss also nicht nur schnell laufen, sondern sich währenddessen auch konzentrieren und zurechtfinden. Die Spezialkarten dafür sind sehr detailliert, dort ist fast jedes Dickicht eingezeichnet. Meine Laufzeit liegt bei etwa 60 Minuten, je nach genauer Distanz. Die Orientierungsläufe kommen ursprünglich aus dem skandinavischen Raum, inzwischen gibt es sie weltweit. Und auch ich komme dank des Sports ganz schön herum - zuletzt war ich beispielsweise in der Schweiz und in New Hampshire in den USA. Über die Jahre bin ich 45 Mal Deutscher Meister im Orientierungslauf geworden, zwei Mal sogar Weltmeister. So ein normaler Straßenlauf wie beim Spendenlauf ist also eigentlich gar nicht meine Disziplin.

\section{Was war denn dann Ihre Motivation, beim Spendenlauf mitzumachen?}

Mit meiner Praxisgemeinschaft bin ich ja auch Platinspender für das Geburtshaus. Da fand ich den Spendenlauf zugunsten des Hauses eine tolle Initiative und bin begeistert von dem Engagement der Firma Beckelmann. Auf dem Röntgenkongress in Hamburg habe ich deshalb auch beim Ausrichten des ersten Spendenlaufs mitgehol-

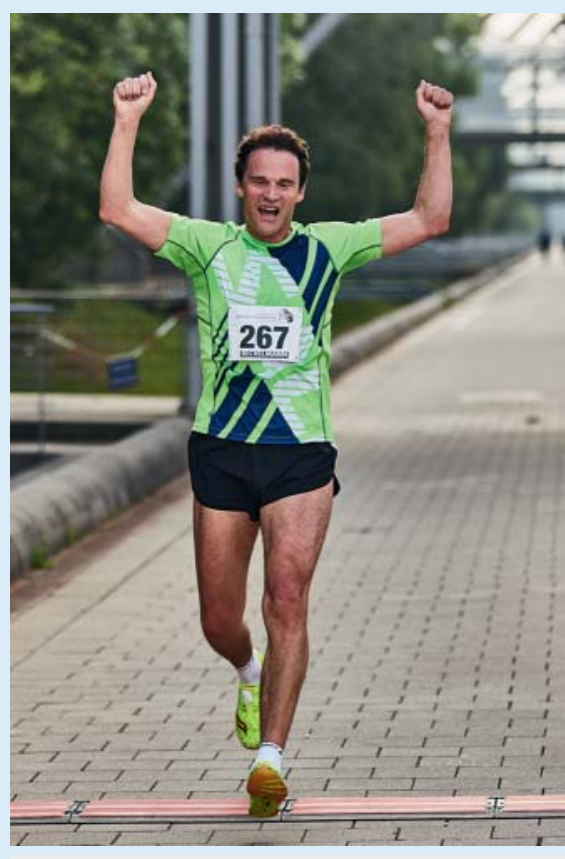

Voller Einsatz für das Röntgen-Geburtshaus: Dr. Michael Finkenstaedt im Spendenlaufziel beim 98. Röntgenkongress.

fen. Jedes Jahr finden die Läufe viel Resonanz. Dabei geht es ja vor allem ums Mitmachen. Das ist auch für mich jedes Mal wieder spannend, denn bei den anderen Wettkämpfen, an denen ich teilnehme, kenne ich meine Konkurrenz. Beim Spendenlauf nicht - ich habe keine Ahnung, ob jemand Schnelleres dabei ist.

Welchen Bezug haben Sie zu Wilhelm Conrad Röntgen - und was bedeutet sein Geburtshaus für Sie?

Wilhelm Conrad Röntgen ist meine Passion. $\mathrm{Er}$ ist eine der bedeutendsten Persönlichkeiten Deutschlands und international sehr bekannt. Gerade wir als Radiologen können wirklich stolz auf ihn sein. Die Neugestaltung des Geburtshauses finde ich eine gute Idee - man hätte ja auch einfach eine Statue in Würzburg errichten können. Aber ein Haus, das die Fachwelt und die breite Öffentlichkeit einlädt, ist einfach schön. Noch war ich nicht selbst vor Ort in Remscheid-Lennep, aber ich hoffe, dass ich zur Einweihung 2019 dabei sein kann.

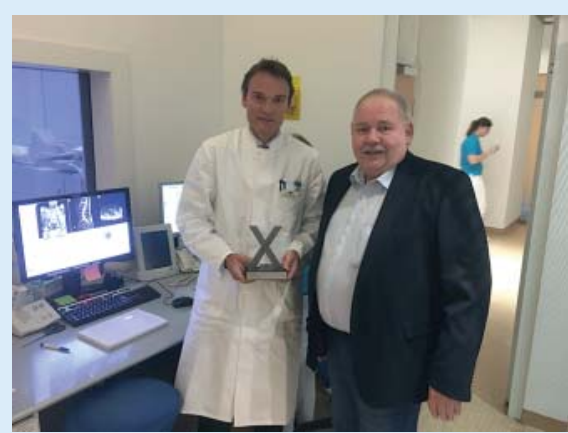

Drei Mal nacheinander gewann er den Spendenlauf - nun darf der markante Pokal in seiner Praxis bleiben: Dr. Michael Finkenstaedt bei der Übergabe durch Peter Beckelmann, dessen Firma die Spendenläufe seit 2015 ausrichtet.

Sie sind niedergelassener Radiologe in Hamburg. Haben Sie eine bestimmte Spezialisierung?

Mein Schwerpunkt ist die Neuroradiologie hierzu habe ich ein Fellowship in den USA gemacht. Anschließend habe ich mich für eine eigene Privatpraxis und gegen eine Unilaufbahn entschieden. Mit Blick auf die Praxislandschaft und meinen Erfahrungen aus den USA dachte ich mir: die Dienstleistungen rund um die Radiologie kann ich besser anbieten. Tja, und dann habe ich einfach angefangen und meine Praxis 1998, also vor fast 20 Jahren, gegründet. Damals waren es drei Mitarbeiter, heute sind es 28. Die Neuroradiologie ist bis heute mein Alleinstellungsmerkmal, zusammen mit meiner sportlichen Wettkampferfahrung. Weil ich selbst Sportler bin, genieße ich eine hohe Glaubwürdigkeit bei den zuweisenden Orthopäden, sie schicken Profisportler und ehrgeizige Freizeitsportler zu mir. Schließlich ist man ein besseres Vorbild, wenn man selbst wettkampferprobt ist.

\section{Vielen Dank für das Gespräch!}

